\title{
Conservation of the function counts: homologous neurons express sequence-related neuropeptides that originate from different genes
}

\author{
Susanne Neupert,* Wolf Huetteroth, $\dagger$ Joachim Schachtner† and Reinhard Predel* \\ *Institute of Zoology, Friedrich Schiller, University of Jena, Jena, Germany \\ $\dagger$ Department of Biology, Animal Physiology, Philipps University of Marburg, Marburg, Germany
}

\begin{abstract}
By means of single-cell matrix assisted laser desorption/ ionization time-of-flight mass spectrometry, we analysed neuropeptide expression in all FXPRLamide/pheromone biosynthesis activating neuropeptide synthesizing neurons of the adult tobacco hawk moth, Manduca sexta. Mass spectra clearly suggest a completely identical processing of the pheromone biosynthesis activating neuropeptide-precursor in the mandibular, maxillary and labial neuromeres of the subesophageal ganglion. Only in the pban-neurons of the labial neuromere, products of two neuropeptide genes, namely the pban-gene and the capa-gene, were detected. Both of these genes expressed, amongst others, sequence-related neuropeptides (extended WFGPRLamides). We speculate that the expression of the two neuropeptide genes is a plesiomorph
\end{abstract}

character typical of moths. A detailed examination of the neuroanatomy and the peptidome of the (two) pban-neurons in the labial neuromere of moths with homologous neurons of different insects indicates a strong conservation of the function of this neuroendocrine system. In other insects, however, the labial neurons either express products of the fxprl-gene or products of the capa-gene. The processing of the respective genes is reduced to extended WFGPRLamides in each case and yields a unique peptidome in the labial cells. Thus, sequence-related messenger molecules are always produced in these cells and it seems that the respective neurons recruited different neuropeptide genes for this motif.

Keywords: CAPA-peptides, FXPRLamides, insects, MALDITOF mass spectrometry, prohormone processing.

J. Neurochem. (2009) 111, 757-765.
In the 'early years' of neuropeptide research, bioactive peptides were isolated using bioassays and time consuming biochemical methods for the separation and identification of the respective compounds. With these methods, only few peptides could be identified at the same time but the bioassays with native material assured, to a certain degree, the physiological relevance of the purified substances. Today, easily obtainable gene sequences are translated into precursor sequences, and putative processing products can be predicted by programs such as NeuroPred (http://neuroproteomics. scs.uiuc.edu/neuropred.html), that search for cleavage sites typical of specific organisms (Amare et al. 2006; Southey et al. 2006). Particularly in insects, the genomic informa tion is by no means correlated with experimental data regarding neuropeptide expression in many species. If expression studies are performed (Predel et al. 2004; Hummon et al. 2006; Predel and Neupert 2007; Li et al. 2008), the difference between predicted and detected neuropeptides is often seen as a result of incomplete peptidomic analysis. Such assumptions tend to reduce the value of peptidomic analyses considerably. Recent and detailed analyses of the expression of insect neuropeptides at the cellular level, however, confirmed that the prediction and the expression do not necessarily match (see Neupert et al. 2007).

Received May 12, 2009; revised manuscript received July 23, 2009; accepted August 17, 2009.

Address correspondence and reprint requests to Susanne Neupert or Reinhard Predel, Institute of Zoology, University of Jena, Erbertstrasse 1, D-07743 Jena, Germany. E-mail: mail@susanne-neupert.de; reinhard.predel@uni-jena.de

Abbreviations used: DH, diapause hormone; MALDI-TOF MS, matrix assisted laser desorption/ionization time-of-flight mass spectrometry; $\mathrm{M}_{\mathrm{Lb}}$, median neurosecretory neurons of the labial neuromere; $\mathrm{M}_{\mathrm{Md}}$, median neurosecretory neurons of the mandibular neuromere; $\mathrm{M}_{\mathrm{Mx}}$, median neurosecretory neurons of the maxillary neuromere; NCC, nervus corporis cardiaci; NGS, normal goat serum; PBAN, pheromone biosynthesis activating neuropeptide; PBST, phosphate-buffered saline containing $0.3 \%$ TritonX-100; PK, pyrokinin; PVK, periviscerokinin; SEG, subesophageal ganglion; SGNP, subesophageal ganglion neuropeptide. 
In this study, we performed an extensive evaluation of pheromone biosynthesis activating neuropeptide (PBAN) synthesizing neurons of an insect to test the importance of peptidomic approaches on the single cell level. Single cell matrix assisted laser desorption/ionization time of flight mass spectrometry (MALDI TOF MS), which already resulted in numerous novel findings about cell signalling and precursor processing of neuropeptides were first per formed on giant neurons of molluscs (van Veelen et al. 1993). Mass spectrometric analyses of single neurons of insects, however, were published only rarely (Ma et al. 2000; Neupert and Predel 2005; Neupert et al. 2007). Obviously, the proper identification and dissection of small insect neurons is more crucial than the mass spectrometric analysis itself. For the following reasons, we have chosen the peptides of the pban gene of Manduca sexta (Xu and Denlinger 2004) for our test case. (i) These peptide hormones belong to the most intensely studied neuropeptides of insects. PBAN and $\mathrm{C}$ terminal related peptides of the pban gene belong to the FXPRLamides which may have entirely different functions in different insects (see Predel and Nachman 2006). In female moths, these peptides regulate pheromone biosynthe sis by directly activating receptors on the pheromone gland cells. To date, the pban gene is known from no less than 19 moth species and numerous immunocytochemical, and in situ hybridisation studies in various lepidoptera led to similar results (see Rafaeli 2008). Moreover, knowledge about the peptides that result from precursor processing is rather unsatisfying and only the occurrence of pban gene products from Helicoverpa zea has been analysed by MALDI TOF MS so far (Ma et al. 2000). (ii) The morpho logy of the PBAN immunoreactive neurons in the subeso phageal ganglion (SEG) of $M$. sexta is very well known from a detailed study by Davis et al. (1996) (iii) Homologous neurons were recently analysed in the SEG of Periplaneta americana (Predel et al. 2007). This analysis suggested a different distribution of FXPRLamides in the different neuromeres of the cockroach SEG that was not found in holometabolous insects so far.

Our results confirm the importance of a systematic evaluation of gene expression and precursor processing at the single cell level. Besides few corrections of the pban gene sequence of $M$. sexta, numerous truncated and abundant FXPRLamides, which are likely to compete with PBAN at the same receptor(s), are described. In contrast to the data presented for the PBAN neurons of H. zea (Ma et al. 2000), all pban neurons in the SEG contained identical products of the pban gene, which were also found in the respective neurohemal release sites. The two pban cells of the labial neuromere, however, expressed products of the capa gene as well. A detailed comparison of the peptidome of the pban neurons of moths with homologous neurons of other insects (Drosophila melanogaster, P. americana) indicates that the pban neurons of the labial neuromere of insects use different neuropeptide genes to express a specific motif (WFGPRLa mide) that activates a specific receptor (Cazzamali et al. 2005).

\section{Materials and methods}

\section{Insects}

Manduca sexta (Lepidoptera: Sphingidae) were raised on an artificial diet under long day photoperiod ( $\mathrm{L}: \mathrm{D}=17: 7)$ at $26^{\circ} \mathrm{C}$ in walk in environmental chambers. Under these conditions, the time required from hatching to pupal ecdysis is about 18 days, and the time from pupal to adult ecdysis is about 20 days. For experiments, adult female moths 04 days after emergence were used.

\section{Immunocytochemistry}

Brains of freshly enclosed adults were dissected under fixative [4\% paraformaldehyde in $0.01 \mathrm{M}$ phosphate buffered saline (PBS) $\mathrm{pH}$ 7.2], transferred to fresh fixative and kept over night at $4^{\circ} \mathrm{C}$. After washing, brains were pre incubated with $5 \%$ normal goat serum (NGS; Jackson Immuno Research, West Grove, PA, USA) in PBS containing 0.3\% TritonX 100 (PBST; Sigma Aldrich, Taufkirchen, Germany) for 2 days at $4^{\circ} \mathrm{C}$. As primary antibodies, we used a polyclonal anti Pea periviscerokinin 2 (PVK 2) serum raised in rabbit at a concentration of $1: 4000$ (kindly provided by Dr M. Eckert, Jena) (Predel et al. 1998). To selectively label neuropil structures, we applied a monoclonal anti synapsin I antibody (SYNORF1; 1 : 100; kindly provided by Dr E. Buchner, Würz burg); its specificity in $M$. sexta was demonstrated recently (Utz et al. 2008). Antisera were diluted in PBST containing $1 \%$ NGS and $0.02 \%$ sodium azide and applied together for 8.5 days at $4{ }^{\circ} \mathrm{C}$. After washing, brains were incubated with $\mathrm{Cy} 3$ coupled goat anti rabbit antisera and Cy5 coupled donkey anti mouse antisera (both Jackson Immuno Research). Both secondary antisera were used at a $1: 300$ dilution in PBST containing 1\% NGS and normal donkey serum (Jackson Immuno Research) and applied for 5 days at $4{ }^{\circ} \mathrm{C}$. Sub sequently, brains were washed, dehydrated (30 95\%, $2 \times 100 \%$ ethanol for 12 min each), and cleared in methyl salicylate (Merck, Darmstadt, Germany). After the tissue has completely cleared, the brains were embedded in Permount (Fisher Scientific, Pittsburgh, PA, USA) between two coverslips using ten plastic reinforcement rings (Herlitz PBS AG, Berlin, Germany) as described before (Huetteroth and Schachtner 2005).

\section{Data acquisition and 3D reconstruction}

Optical sections ( 8 bit, $1024 \times 1024$ pixel) for both channels were obtained sequentially using the $543 \mathrm{~nm}$ and $633 \mathrm{~nm}$ laser line of a confocal laser scanning microscope (Leica TCS SP2) equipped with a $10 \times$ objective (HC PL APO 10×/0.4 Imm Corr CS; Leica, Bensheim, Germany). For the brain, three overlapping optical stacks with a voxel resolution of approximately $1.45 \times 1.45 \times 1.8 \mu \mathrm{m}$ were taken from both sides of the preparation. Three D reconstruction was performed in AMIRA 4.1 (Visage Imaging, Fürth, Germany (el Jundi et al. 2009).

Dissection of cell bodies and sample preparation for mass spectrometry

For single cell dissections, isolated ganglia were fixed with micro needles and the ganglionic sheath was disrupted using ultra fine 
scissors. Somata of neuroendocrine cells in the SEG were detected as a result of their slightly bluish colour. Without enzyme treatment, these neurons were removed step by step using an uncoated glass capillary (Hilgenberg $\mathrm{GmbH}$, Malsfeld, Germany) and transferred to a stainless steel sample plate for MALDI TOF MS. The insect saline was subsequently removed using the same capillary. Approximately $10 \mathrm{ml}$ of matrix solution was injected onto the dried cell over a period of about $5 \mathrm{~s}$ using a Nanoliter injector (World Precision Instruments, Berlin, Germany). Two matrix solutions were used in the experiments: $\alpha$ cyano 4 hydroxycinnamic acid dissolved in methanol/water $(1: 1)$ and 2,5 dihydroxybenzoic acid dissolved in $25 \%$ acetonitrile $/ 0.1 \%$ trifluoroacetic acid. 2,5 dihydroxybenzoic acid allowed the detection of larger neuropeptides that generated no or weak signals when $\alpha$ cyano 4 hydroxycinnamic acid was used. On the other hand, $\alpha$ cyano 4 hydroxycinnamic acid resulted in mass spectra with better reproducible ion abundances. Each preparation was air dried and the samples that were prepared with $\alpha$ cyano 4 hydroxycinnamic acid were additionally rinsed with pure water for a few seconds.

MALDI-TOF mass spectrometry

MALDI TOF mass spectra were acquired in positive ion mode on an Ultraflex II TOF/TOF (Bruker Daltonics, Bremen, Germany) equipped with LIFT technology. All acquisitions were taken in manual mode. Initially, the instrument was operated in reflectron mode to determine the parent masses. Metastable fragment ions that have been generated by laser induced decomposition were post accelerated in the LIFT module (Ultra flex TOF/TOF system) and delivered MS/MS spectra. The fragmentation data obtained in these experiments were handled using the FlexAnalysis 3.0 (Bruker Daltonics, Bremen, Germany) software package. An external mass spectrum calibration was first performed using synthetic peptides. Samples with peptides that contained Lys/Gln ambiguities were analysed again after dissolv ing the respective preparations in acetic anhydride $(2: 1$ methanol/acetic anhydride), which resulted in selective acetylation of the $\varepsilon$ amino group of Lys.

\section{Results}

Immunostainings and in situ hybridization experiments in many moth species have shown that the pban gene is exclusively expressed in neurons of the SEG (see Rafaeli 2008). By means of an anti PVK 2 (extended PRVamide) serum (Predel et al. 2007), the putative PBAN expressing neurons of $M$. sexta were labelled (Fig. la). To examine the projection pattern of the different pban neurons, we per formed 3D reconstructions of confocal image stacks obtained from wholemount immunostainings (Fig. 1b, Movie S1 in Supporting Information). In the mandibular neuromere, four immunoreactive cells were found in the midline $\left(\mathrm{M}_{\mathrm{Md}}\right)$. Their neurites enter, together with the neurites of six PBAN immunoreactive neurons of the maxillary neuromere $\left(M_{M x}\right)$, the maxillary nerve (Fig. 1). In the labial neuromere, a pair of PBAN immunoreactive neurons $\left(\mathrm{M}_{\mathrm{Lb}}\right)$ was detected with neurites projecting via the nervi corporis cardiaci 3 (NCC 3 ) to the retrocerebral complex.

Immunostained somata were not suitable for our mass spectrometric analyses. The median neurosecretory neurons in the SEG of moths are, however, easily detectable because of their slightly bluish colour. Thus, retrograde filling for cell identification prior to mass spectrometric analysis (Neupert and Predel 2005) was not necessary. In our experiments, the somata of the PBAN expressing neurons of the SEG (see Fig. 1) were step by step dissected and directly transferred to a MALDI sample plate. The resulting mass spectra of the mandibular ( 4 cells analysed) and maxillary neurons ( 9 cells analysed) (Fig. 2a and b) were nearly identical regarding occurrence and signal intensity of ion signals. Few sub stances in the higher mass range ( $36 \mathrm{kDa}$ ) were only detectable when 2,5 dihydroxybenzoic acid was used as matrix solution (Fig. 3). For peak identification, the mass
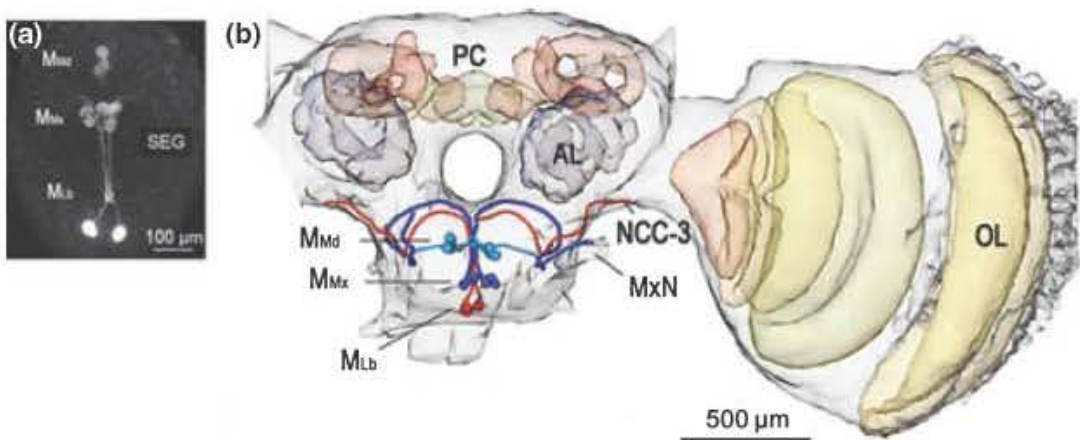

Fig. 1 Localisation and projection of pban neurons in the CNS of $M$. sexta. (a) Microphotograph of an anti PVK 2 immunostaining from a wholemount preparation of the subesophageal ganglion (SEG). Three cell clusters in the mandibular ( $M_{M d}$, four cells), maxillary ( $M_{M x}$, six cells) and labial ( $\mathrm{M}_{\mathrm{Lb}}$, two cells) neuromere are stained. (b) Three dimensional reconstruction of confocal image stacks obtained from whole mount anti PVK 2 immunostaining (anterior view, for full view see Video Clip S1). Axonal projections of the three median cell clus ters enter the dorsal neuropile and project laterally. Neurites of the $M_{M d}$ and $M_{M x}$ cells project via maxillary nerves ( $M x N$ ) into the retro cerebral complex. The axons of the labial cell group $\left(\mathrm{M}_{\mathrm{Lb}}\right)$, however, leave the CNS via nervi corporis cardiaci 3 (NCC 3 ) to innervate the retrocerebral complex. 
(a) $3.0 \mathrm{E}+4 \mathrm{y}-\mathrm{SGNP}$

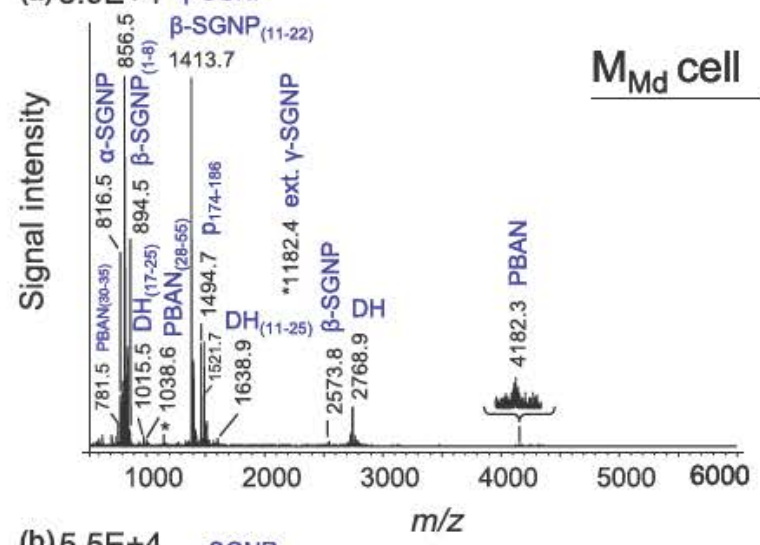

(b) $5.5 \mathrm{E}+4 \quad \mathrm{y}$-SGNP

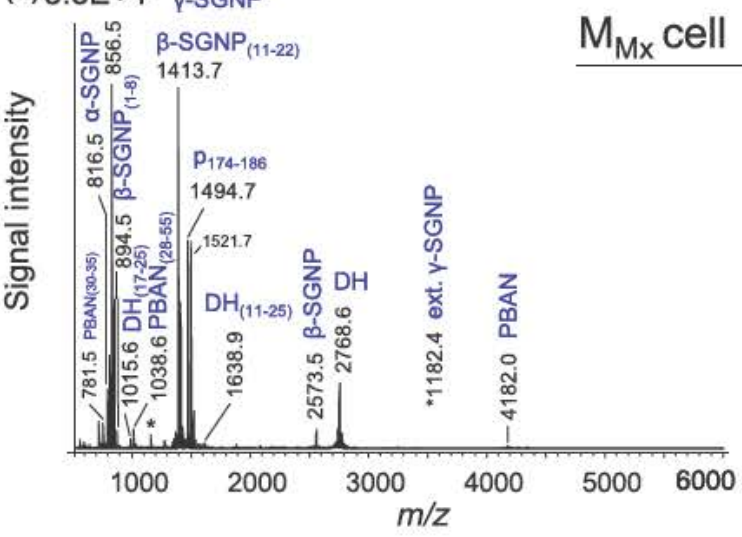

Fig. 2 Representative MALDI TOF mass spectra obtained from single pban neurons of the SEG. Prior dissection, neurons were identified because of their bluish colour (Tyndall effect). The preparations of the different neurons yielded nearly identical results regarding occurrence and signal intensity of neuropeptides; only products of the $M$. sexta pban gene were detected. (a) $M_{M d}$, neurosecretory cell of the mandibular neuromere. (b) $\mathrm{M}_{\mathrm{M} \times}$, neurosecretory cell of the maxillary neuromere.

signals were compared with the calculated protonated molecular weights of peptides derived from the $M$. sexta PBAN precursor. Only two of the five predicted FXPRLa mides [PBAN, diapause hormone (DH), $\alpha, \beta, \gamma$ subesoph ageal ganglion neuropeptide (SGNP)] could be assigned, namely PBAN and $\gamma$ SGNP. In addition, a number of abundant ion signals were found to be mass identical with other predictable or truncated peptides from the PBAN precursor. Prominent ion signals of peptides which could not be assigned to products of the pban gene were subsequently fragmented by tandem MS (Fig. 4). This approach yielded the remaining FXPRLamides ( $\mathrm{DH}, \alpha, \beta$ SGNP). DH was initially not detected as the predicted position of the $\mathrm{N}$ terminal cleavage site was not correct, $\alpha$ SGNP contained Lys instead of Glu at the penultimate position, and an internal Phe has to be removed from the sequence of the predicted $\beta$ SGNP. After the sequence elucidations of the unknown peptides in mass spectra of the $\mathrm{M}_{\mathrm{Md}}$ and $\mathrm{M}_{\mathrm{Mx}}$ neurons, most

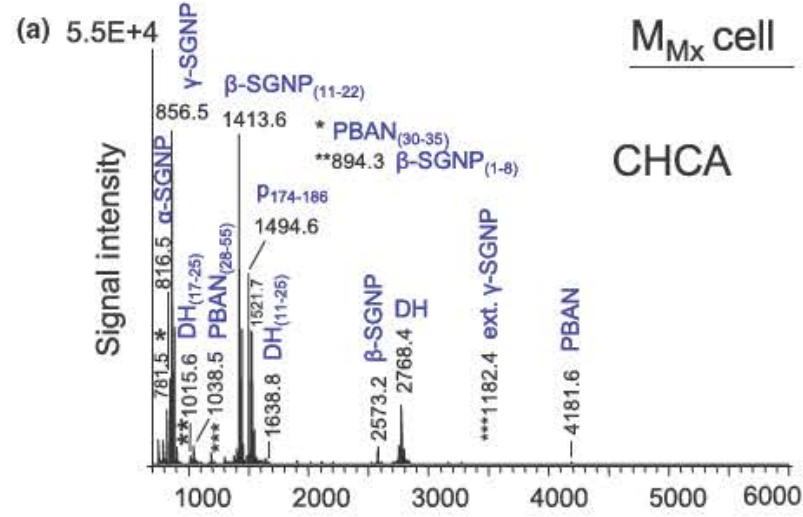

(b) $3.5 \mathrm{E}+4$

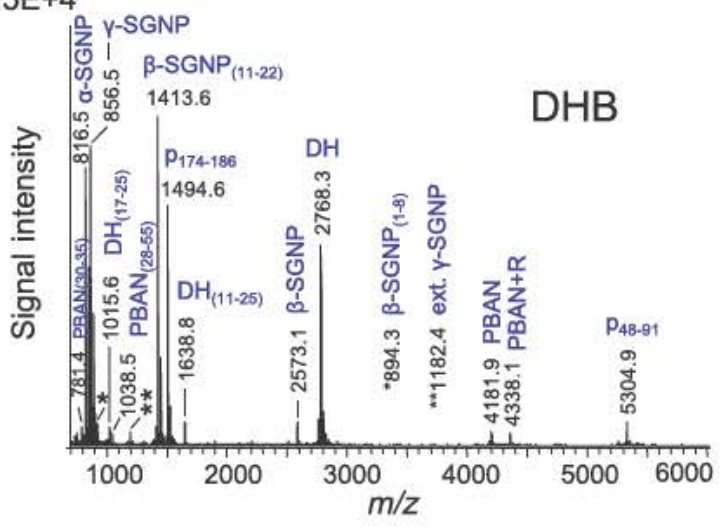

Fig. 3 Comparison of mass spectra from preparations of $M_{M x}$ cells which were prepared using different matrix solutions. (a) $\alpha$ Cyano 4 hydroxycinnamic acid in 1:1 methanol/water. (b) 2,5 dihydroxyben zoic acid in $25 \%$ acetonitrile/0.1\% TFA; revealing some additional neuropeptides in the higher mass range (i.e. PBAN + R, P48 91) that were rarely detectable with $\alpha$ cyano 4 hydroxycinnamic acid as matrix salt.

of the ion signals could be assigned to the products of the pban gene (see Table 1); the relative abundances of the different products of the pban gene were largely constant in the different mass spectra.

The number of cleavage products is higher than originally anticipated. A schematic overview about the processing of the pban gene is given in Fig. 5. The products of the pban gene, which were detected in the $\mathrm{M}_{\mathrm{Md}}$ and $\mathrm{M}_{\mathrm{Mx}}$ neurons are likely to be released in the haemolymph. This was supported by profiling the maxillary nerves that contain axons of the $\mathrm{M}_{\mathrm{Md}} /$ $\mathrm{M}_{\mathrm{Mx}}$ neurons (not shown). All products of the pban gene typical of the $\mathrm{M}_{\mathrm{Md}}$ and $\mathrm{M}_{\mathrm{Mx}}$ somata were also found in spectra of neurosecretory neurons from the labial neuromere ( 6 cells analysed) (Fig. 6a). Mass spectra from these neurons, however, contained additional prominent peptide signals that could be assigned to the products of the capa gene (Loi and Tublitz 2004). CAPA peptides (periviscerokinins $/ \mathrm{CAP}_{2}$ bs and a single FXPRLamide) are typical of the median neurosecre tory cells in the abdominal ganglia of all insects studied so 


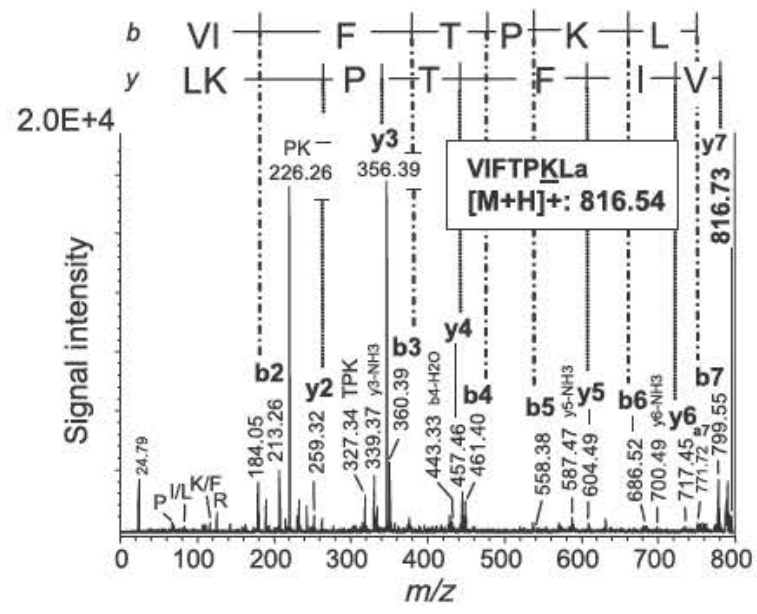

Fig. $4 \mathrm{CID}$ mass spectrum of the ion signal at $[\mathrm{M}+\mathrm{H}]^{+}: 816.54 \mathrm{Da}$ (see Figs 2 and 3) under condition of high gas. A number of $y, a$ and $b$ type ions are labelled. The fragments were analysed manually and the resulting sequence is given. Assignment of the Lys/Gln ambiguity was revealed in a subsequent experiment by means of on plate acetylation with acetic anhydride (not shown). Thus, $\alpha$ SGNP contains a Lys instead of the predicted Glu as the penultimate amino acid.

far (Predel and Wegener 2006), and are usually stored in abdominal perisympathetic organs. A mass spectrum taken from a single abdominal perisympathetic organ of $M$. sexta (Fig. 6b) indeed contained all products of the capa gene that were found in the labial cells. Thus, the labial cells express the products of two neuropeptide genes, these peptides were also found in mass spectra of the NCC 3 (not shown) which contains the axons from the $\mathrm{M}_{\mathrm{Lb}}$ neurons. The processing of the CAPA precursor is summarized in Fig. 7.

\section{Discussion}

This study was initiated to get an overview about processing of the pban prohormone in the tobacco hawk moth $M$. sexta; a pest of considerable agricultural importance. We found more cleavage products than expected. Finally, we detected all predictable products of the pban and capa gene in the respective somata, and the presence of these peptides in peripheral nerves suggests that the peptides are packaged into vesicles. Amongst those products were many FXPRLamides, which likely compete on the same receptor(s) (see Abernathy et al. 1995; Rafaeli 2008). These FXPRLamides occupy a high hierarchic position in the regulation of pheromone production in female moths (Raina and Klun 1984); the pheromones are essential to attract the males. At first glance, the results yielded nice but mainly species specific insights into PBAN prohormone processing and provided sufficient data to correct errors in the prohormone sequence. A systematic analysis of the results, however, shows astonish ing novelties that are of general interest and can be directly assigned to the method of single cell analysis. In a revealing examination of pban neurons of the moth $H$. zea, Ma et al. (2000) detected already a number of cleavage products of the Hez pban gene by using MALDI TOF MS. This analysis of neuroendocrine cell clusters in the SEG led to the assumption that the mandibular, maxillary and labial pban neurons contain peptides, in addition to the FXPRLamides, that are unique to each neuromere, respectively (Ma et al. 2000). This is, however, not the complete story. A mass spectro metric survey of cell clusters in the nervous system usually presents products of different cell types, even if the dissected somata are uniform. This paradox can often be traced back to the fact, that attached nerve fibres which are not detectable during the dissection, contaminate the samples. Thus, reducing the sample complexity from tissues/cell clusters to single cells reduces the complexity of the peptidome and may lead to the detection of peptides that are otherwise obscured. In addition, single cell analysis offers an unambiguous information about colocalization of neuropeptides. Exactly, these phenomena were found in our own analyses. Mass spectra of properly identified and dissected pban neurons yielded signal to noise ratios that were not obtained from preparations of the respective cell clusters (not shown). Particularly impressive was the uniform relative signal intensity of the different products of the PBAN prohormone in the different single cell spectra. These mass spectra clearly suggested a completely identical processing of the PBAN precursor in SEG neurons. The pban cells of the mandibular and maxillary neuromeres exclusively contain products of the pban gene and project into the maxillary nerves/retroce rebral complex, which contain these neuropeptides as well. This verified that peptides of the pban gene which were detected in somata of the pban neurons, are indeed putative peptide hormones. Homologous neurons of other insects show exactly the same pattern, only the specific peptide sequences diverged (Melcher and Pankratz 2005; Neupert et al. 2007; Predel et al. 2007). Even the projection of the neuroendocrine SEG neurons in the mandibular and maxil lary neuromeres (see Fig. 1) did not change, obviously, since more than 200 million years. In cockroaches and locusts as well as in moths, the neurites of the respective somata $\left(\mathrm{A} 1=\mathrm{M}_{\mathrm{Md}}, \mathrm{A} 2=\mathrm{M}_{\mathrm{Mx}}\right)$ project dorsally and leave the SEG via nervi corporis allati 2 (corresponds to the maxillary nerve of Lepidoptera) to reach the retrocerebral complex (Bräunig et al. 1996; Davis et al. 1996; Predel et al. 2007). Drosophila with its many apomorphic reductions typical of brachyceran flies, expresses a single FXPRLamide in the homologous neurons [hugin neurons; (Meng et al. 2002; Neupert et al. 2007)], which is transported via the NCC to the retrocerebral complex. A nerve leaving the SEG to the retrocerebral complex did not persist in these flies.

The strong conservation of the peptidergic system in the SEG of insects is also typical of the labial neuromere, at least regarding the projection pattern. The neurites of the $\mathrm{M}_{\mathrm{Lb}}$ neurons of $M$. sexta project anteriorly, cross the neurites of 


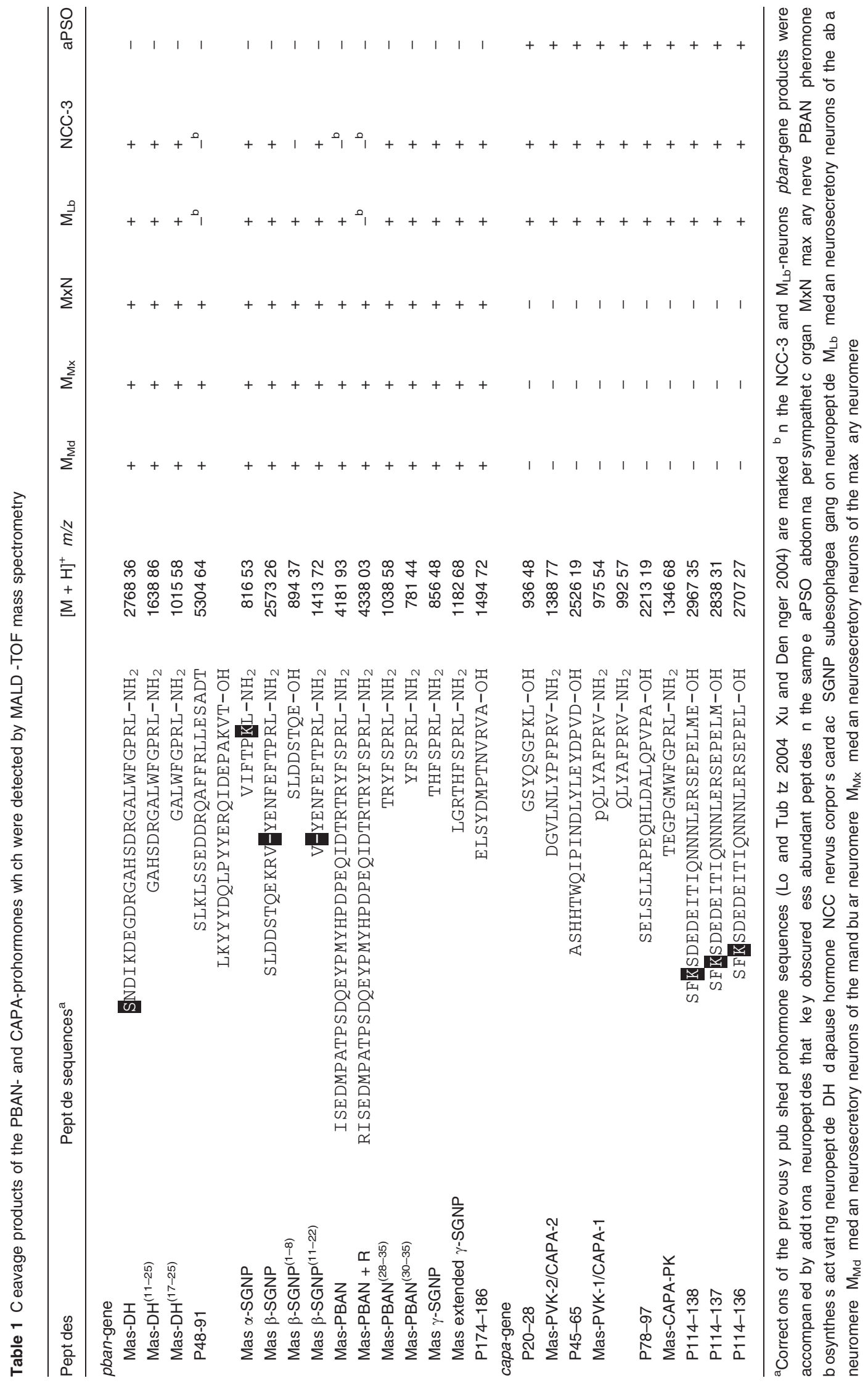




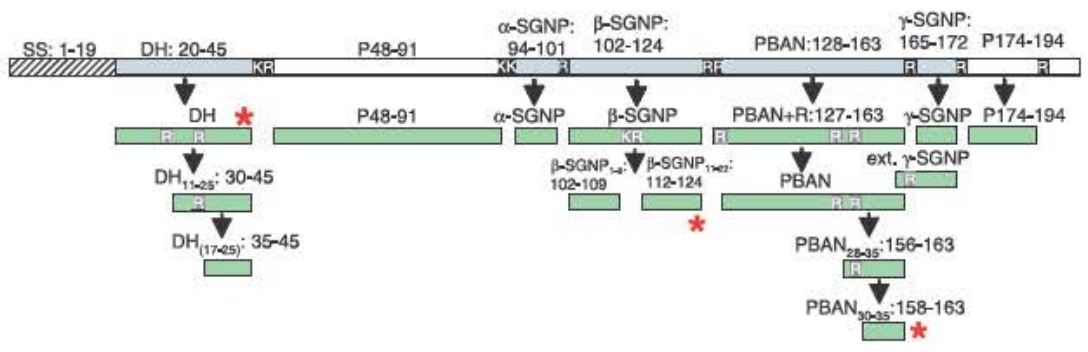

Fig. 5 Overview of the Manduca pban prohormone processing in the SEG neurons as indicated by single cell mass spectrometry. Cleavage sites are represented by black or hatched bars and previously pre dicted products (Xu and Denlinger 2004) are represented by blue bars.

the $\mathrm{M}_{\mathrm{Md}}$ and $\mathrm{M}_{\mathrm{Mx}}$ cells, enter the circumesophageal connectives and leave the CNS via the NCC 3 (Davis et al. 1996; Fig. 1). This projection is also known from locusts (Bräunig 1990) and cockroaches (Predel et al. 2007); Drosophila does not develop an NCC 3. A remarkable
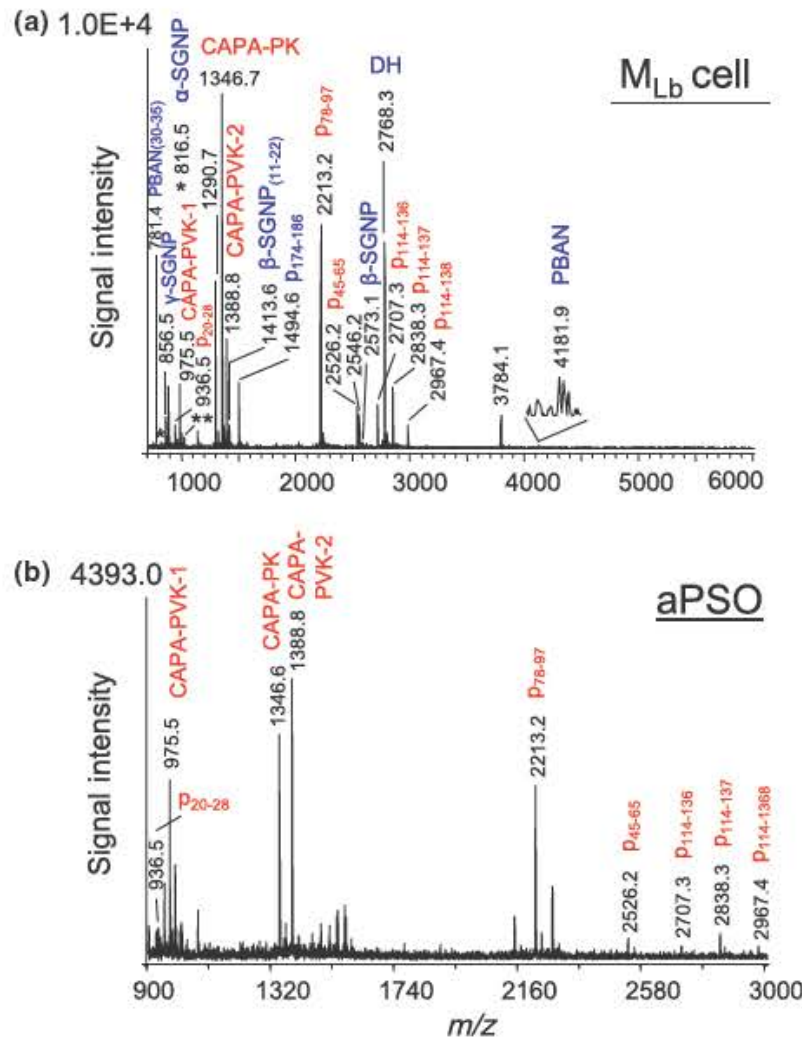

Fig. 6 Representative MALDI TOF mass spectra from (a) a prepa ration of a single neuron of the labial neuromere $\left(\mathrm{M}_{\mathrm{LB}}\right)$ of the SEG which sends its axon via the NCC 3 into the retrocerebral complex. Not only products of the pban gene but also products of the capa gene are detectable. This is different from the peptidome of pban express ing cells in the mandibular and maxillary neuromere. (b) A preparation of an abdominal PSO of larvae, which results in CAPA peptides only. Clearly, capa gene expression in the SEG and abdominal ganglia yielded the identical CAPA peptides.
All products of the pban gene, which could be identified by mass spectrometry, are labelled in green. Truncated forms of DH, $\beta$ SGNP and PBAN were detected as well. In these cases, the forms with the highest signal intensity in mass spectra are marked with asterisks.

difference, however, exists regarding the neuropeptide expression in these insect neurons. The fact that the pepti dome of the labial cells is distinctly different from the peptidome of the FXPRLamide expressing cells of the mandibular and maxillary neuromeres is typical of all insects studied so far. This is usually obscured in immunostainings, since at least a single FXPRLamide is present in the labial cells of different insects. What are the differences between the various insect groups? In basal hemimetabolous insects, e.g. cockroaches, the putative FXPRLamide prohormone is differentially cleaved in mandibular/maxillary neurons on the one hand and labial neurons on the other hand, which suggests a difference in the enzyme complement of these cells (Predel et al. 2007). The subset of FXPRLamides, which is detectable in labial cells of cockroaches, consists of extended WFGPRLamides only. In D. melanogaster, a receptor with high affinity to WFGPRLamides was described (Cazzamali et al. 2005), in addition to another receptor that recognizes the remaining FXPRLamide(s) (Park et al. 2002; Rosenkilde et al. 2003). Peptides with the C terminal hexapeptide WFGPRLamide are encoded in the fxprl gene of many insects, not so in D. melanogaster. In this species, the only extended WFGPRLamide is encoded on the capa gene, and it is probably no coincidence that the capa gene instead of the fxprl gene is expressed in labial cells of $D$. melanogaster (Kean et al. 2002). The homology of the Drosophila capa neurons in the SEG with the ventral posterior median (VPM) neurons of cockroaches and the $\mathrm{M}_{\mathrm{Lb}}$ neurons of moths has still to be confirmed, but the projection of these Drosophila neurons to the retrocerebral complex strongly suggests a homology. If so, homologous neurons would release very similar peptides, which activate homologous receptors, although different genes are ex pressed. In light of this thought experiment, the differential processing of the capa gene in neuroendocrine neurons of the abdominal ventral nerve cord and those of the SEG (Predel et al. 2004; Wegener et al. 2006) would make sense. The capa neurons in the SEG only produce the CAPA pyrokinin (PK), not the CAPA PVKs. CAPA PVKs activate different receptors (Iversen et al. 2002). The prohormone 


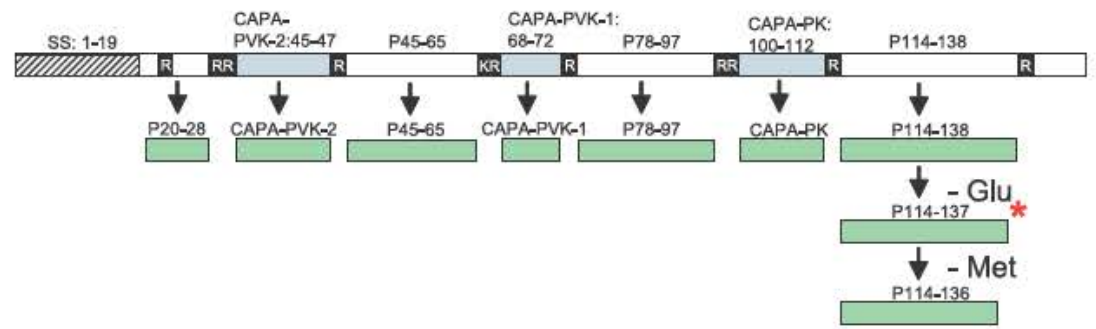

Fig. 7 Overview of the Manduca capa prohormone processing as indicated by mass spectrometric analysis of $\mathrm{M}_{\mathrm{Lb}}$ neurons and abdominal PSOs. Cleavage sites are represented by black or hatched bars and previously predicted products (Loi and Tublitz 2004) are

processing in the capa neurons of the abdominal ventral nerve cord, however, yields two CAPA PVKs besides the CAPA PK (Drm PK 1).

What did we find in $M$. sexta? The pban neurons in the labial neuromere of the SEG indeed contained products of two neuropeptide genes, namely the pban gene and the capa gene. In these cells, the prohormones of both genes are cleaved exactly as it has been found for other pban/capa cells of $M$. sexta which is clearly different from the other insect species mentioned above. One may speculate that the expression of two neuropeptide genes in the labial cells is a plesiomorph character; this question can only be solved after the inclusion of further insect taxa. A comparison of the peptidome of the 'pban cells' from the labial neuromeres of $P$. americana, D. melanogaster, and $M$. sexta suggests that in each species, these neurons express products of different genes: either the fxprl gene (P. americana), capa gene ( $D$. melanogaster) or the fxprl gene and the capa gene ( $M$. sexta). What all these neurons have in common is the expression of an extended WFGPRLamide which likely activates a specific receptor (Cazzamali et al. 2005). Thus, all these neurons synthesize sequence related messenger molecules and it seems that the respective neurons recruited different neuropeptide genes for this motif.

Neither the identical processing of the PBAN precursor in all SEG neurons nor the specific peptidome of the labial pban cells was reported after mass spectrometric profiling of the homologous cell clusters in the moth $H$. zea (Ma et al. 2000). In this context, it is noteworthy that many previous immunostainings suggested colocalization in peptidergic neurons of insects as the rule rather than the exception. Recent mass spectrometric analyses, however, did not support this assumption (Neupert and Predel 2005; Neupert et al. 2007; Predel et al. 2007). In fact, the mass spectra from the labial neurons of $M$. sexta are the first mass spectrometric proof of a cellular colocalization of insect neuropeptides that originate from different genes. This finding is yet an another evidence that shows the advantage of single cell MS for a comprehensive survey of prohormone processing in insect neurons. represented by blue bars. All products of the capa gene, which were identified by mass spectrometry, are labelled in green. Truncated forms of P114 138 were detected as well; the form with the highest signal intensity in mass spectra is marked with an asterisk.

\section{Acknowledgements}

We acknowledge the financial assistance of the Deutsche Forschungsgemeinschaft (Predel 595/6 1,2 766/9 1).

\section{Supporting Information}

Additional Supporting Information may be found in the online version of this article:

Movie S1. Animated view of a horizontally rotating Manduca sexta brain 3D reconstruction. Based on anti PVK 2 immunostain ing, all three immunoreactive cell clusters in the subesophageal ganglion were reconstructed, including their primary neurites (compare Fig. 1b). Although all cells innervate the retrocerebral complex, the neurites of the four mandibular cells (light blue) and the six maxillary cells (blue) follow the maxillary nerves, while the neurites of the two labial cells (red) leave via the nervi corporis cardiaci 3. Outlines of distinct neuropilar structures are visible in transparent colours for better orientation.

As a service to our authors and readers, this journal provides supporting information supplied by the authors. Such materials are peer reviewed and may be re organized for online delivery, but are not copy edited or typeset. Technical support issues arising from supporting information (other than missing files) should be addressed to the authors.

\section{References}

Abernathy R. L., Nachman R. J., Teal P. E., Yamashita O. and Tumlinson J. H. (1995) Pheromonotropic activity of naturally occurring pyrokinin insect neuropeptides (FXPRLamide) in Helicoverpa zea. Peptides 16, 215219.

Amare A., Hummon A. B., Southey B. R., Zimmerman T. A., Rodriguez-Zas S. L. and Sweedler J. V. (2006) Bridging neuropeptidomics and genomics with bioinformatics: prediction of mammalian neuropeptide prohormone processing. J. Proteome Res. 5, 11621167.

Bräunig P. (1990) The morphology of suboesophageal ganglion cells innervating the nervus corporis cardiaci III of the locust. Cell Tissue Res. 260, 95108.

Bräunig P., Böhme C. and Stauffer B. (1996) Morphology of locust neurosecretory cells projecting into the Nervus Corporis allati II of the suboesophageal ganglion. Microsc. Res. Tech. 35, 230 241. 
Cazzamali G., Torp M., Hauser F., Williamson M. and Grimmelikhuijzen C. J. (2005) The Drosophila gene CG9918 codes for a pyrokinin-1 receptor. Biochem. Biophys. Res. Commun. 335, 1419.

Davis N. T., Homberg U., Teal P. E., Altstein M., Agricola H. J. and Hildebrand J. G. (1996) Neuroanatomy and immunocytochemistry of the median neuroendocrine cells of the subesophageal ganglion of the tobacco hawkmoth, Manduca sexta: immunoreactivities to PBAN and other neuropeptides. Microsc. Res. Tech. 35, 201229.

Huetteroth W. and Schachtner J. (2005) Standard three-dimensional glomeruli of the Manduca sexta antennal lobe: a tool to study both developmental and adult neuronal plasticity. Cell Tissue Res. 319, 513524 .

Hummon A. B., Richmond T. A., Verleyen P. et al. (2006) From the genome to the proteome: uncovering peptides in the Apis brain. Science 314, 647649.

Iversen A., Cazzamali G., Williamson M., Hauser F. and Grimmelikhuijzen C. J. (2002) Molecular cloning and functional expression of a Drosophila receptor for the neuropeptides capa-1 and -2. Biochem. Biophys. Res. Commun. 299, 628633.

el Jundi B., Huetteroth W., Kurylas A. E. and Schachtner J. (2009) Anisometric brain dimorphism revisited: Implementation of a volumetric 3D standard brain in Manduca sexta. J. Comp. Neurol. $\mathbf{5 1 7}, 210225$

Kean L., Cazenave W., Costes L., Broderick K. E., Graham S., Pollock V. P., Davies S. A., Veenstra J. A. and Dow J. A. (2002) Two nitridergic peptides are encoded by the gene capability in Drosophila melanogaster. Am. J. Physiol. Regul. Integr. Comp. Physiol. 282, R1297 R1307.

Li B., Predel R., Neupert S. et al. (2008) Genomics, transcriptomics, and peptidomics of neuropeptides and protein hormones in the red flour beetle Tribolium castaneum. Genome Res. 18, 113122.

Loi P. K. and Tublitz N. J. (2004) Sequence and expression of the CAPA/ CAP2b gene in the tobacco hawkmoth, Manduca sexta. J. Exp. Biol. 207, 36813691.

Ma P. W., Garden R. W., Niermann J. T., O' Connor M. and Sweedler J. V. (2000) Characterizing the Hez-PBAN gene products in neuronal clusters with immunocytochemistry and MALDI MS. J. Insect Physiol. 46, 221230.

Melcher C. and Pankratz M. J. (2005) Candidate gustatory interneurons modulating feeding behavior in the Drosophila brain. PLoS Biol. 9 , e305.

Meng X., Wahlström G., Immonen T., Kolmer M., Tirronen M., Predel R., Kalkkinen N., Heino T. I., Sariola H. and Roos C. (2002) The Drosophila hugin gene codes for myostimulatory and ecdysis modifying neuropeptides. Mech. Dev. 117, 513.

Neupert S. and Predel R. (2005) Mass spectrometric analysis of single identified neurons of an insect. Biochem. Biophys. Res. Commun. 327, 640645

Neupert S., Johard H. A., Nässel D. R. and Predel R. (2007) Single-cell peptidomics of Drosophila melanogaster neurons identified by Gal4-driven fluorescence. Anal. Chem. 79, 36903694.

Park Y., Kim Y. J. and Adams M. E. (2002) Identification of G proteincoupled receptors for Drosophila PRXamide peptides, CCAP, corazonin, and AKH supports a theory of ligand-receptor coevolution. Proc. Natl Acad. Sci. USA 99, 1142311428.
Predel R. and Nachman R. J. (2006) The FXPRLamide (Pyrokinin PBAN) Peptide Family. in Handbook of Biologically Active Peptides (Kastin A. J., eds), pp. 207 212. Academic Press, Elsevier, Louisiana, USA.

Predel R. and Neupert S. (2007) Social behavior and the evolution of neuropeptide genes: lessons from the honeybee genome. BioEssays 29, 416421.

Predel R. and Wegener C. (2006) Biology of the CAPA peptides in insects. Cell. Mol. Life Sci. 63, 24772490.

Predel R., Rapus J., Eckert M., Holman G. M., Nachman R. J., Wang Y. and Penzlin H. (1998) Isolation of periviscerokinin-2 from the abdominal perisympathetic organs of the American cockroach, Periplaneta americana. Peptides 19, 801809.

Predel R., Wegener C., Russell W. K., Tichy S. E., Russell D. H. and Nachman R. J. (2004) Peptidomics of CNS-associated neurohemal systems of adult Drosophila melanogaster: a mass spectrometric survey of peptides from individual flies. J. Comp. Neurol. 474, 379392.

Predel R., Eckert M., Pollák E., Molnár L., Scheibner O. and Neupert S. (2007) Peptidomics of identified neurons demonstrates a highly differentiated expression pattern of FXPRLamides in the neuroendocrine system of an insect. J. Comp. Neurol. 500, 498512.

Rafaeli A. (2008) Pheromone biosynthesis activating neuropeptide (PBAN): regulatory role and mode of action. Gen. Comp. Endocrinol. 162, 6978.

Raina A. K. and Klun J. A. (1984) Brain factor control of sex pheromone production in the female corn earworm moth. Science 225, 531532.

Rosenkilde C., Cazzamali G., Williamson M., Hauser F., Søndergaard L., DeLotto R. and Grimmelikhuijzen C. J. (2003) Molecular cloning, functional expression, and gene silencing of two Drosophila receptors for the Drosophila neuropeptide pyrokinin-2. Biochem. Biophys. Res. Commun. 309, 485494.

Southey B. R., Amare A., Zimmerman T. A., Rodriguez-Zas S. L. and Sweedler J. V. (2006) NeuroPred: a tool to predict cleavage sites in neuropeptide precursors and provide the masses of the resulting peptides. Nucleic Acids Res. 34, 267272.

Utz S., Huetteroth W., Vömel M. and Schachtner J. (2008) Mas-allatotropin in the developing antennal lobe of the sphinx moth Manduca sexta: distribution, time course, developmental regulation and colocalization with other neuropeptides. Dev. Neurobiol. 68, 123 142.

van Veelen P. A., Jimenez P. R., Li K. W., Wildering W. C., Geraerts W. P., Tjaden U. R. and van der Greef J. (1993) Direct peptide profiling of single neurons by matrix-assisted laser desorptionionization mass sopectrometry. Org. Mass Spectrom. 28, 1542 1546.

Wegener C., Reinl T., Jänsch L. and Predel R. (2006) Direct mass spectrometric peptide profiling and fragmentation of larval peptide hormone release sites in Drosophila melanogaster reveals tagmaspecific peptide expression and differential processing. J. Neurochem. 5, 13621374.

$\mathrm{Xu}$ W. H. and Denlinger D. L. (2004) Identification of a cDNA encoding DH, PBAN and other FXPRL neuropeptides from the tobacco hornworm, Manduca sexta, and expression associated with pupal diapause. Peptides 25, 10991106. 